\title{
Information literacy, transliteracy and information culture development in France: what the teacher- librarian can change
}

\author{
Anne Cordier \\ Anne Lehmans \\ Université de Rouen-IUFM Haute Normandie \\ anne.cordier@univ-rouen.fr \\ Université de Bordeaux IV-IUFM d'Aquitaine, France \\ anne.lehmans@iufm.u-bordeaux4.fr
}

\begin{abstract}
A research project on French high school pupils' information curriculum is for the development of a real media and information culture construction. Researchers have been examining, recording and interviewing 150 pupils in groups and individually during a research activity in 3 different highschools. The project is based on a qualitative, ethnographic methodology to observe information and pupils' transliterate practices on one hand, and the training practices of teachers-librarians on the other hand. The results show the importance of the teacher librarian's commitment on the transliteracy process.
\end{abstract}

Keywords: Transliteracy, information culture, professional training, media and information literacy, teacher-librarian, curriculum on information

\section{Introduction}

Information literacy has been defined in 1989 by the ALA [1] as a set of abilities requiring individuals to "recognize when information is needed and have the ability to locate, evaluate, and use effectively the needed information." It is fundamentally based on a humanistic and universalistic conception of the right to be educated [2] and the project to make education a path to individual empowerment toward information as a source of power. Recently, information literacy has been completed and enlarged by the concept of transliteracy that Sue Thomas, an English scholar, defines as "the ability to read, write and interact across a range of platforms, tools and media from signing and orality through handwriting, print, TV, radio and films, to digital social networks." [3] The interest in transliteracy in research programs is focused on the universe of reading through the "big bang" [4] of the web with new media, materials, sensitive experience, social organizations, cognitive operation and formal characteristics. According to Vincent Liquete [5], the concept of transliteracy focuses the attention on the "trans" prefix: transversality of skills and abilities 
common to all media contexts and techniques, transformation of situations and information by personal practices and procedures, transition from personal to collective knowledge, transgression of academic standards. It is at the crossroad of three main fields: information, media and computer literacies, as well as a metalitteracy.

In France, in every secondary school, a teacher librarian is in charge not only of the school library management and organization, but also of the education on information of all pupils and scholars. The culture of information that they try to build is mainly based on a mediation process implying a certain obliteration of the professor who lets the pupils organize their own path into information within activities, tools, a coaching more than a teaching posture and spaces that he has structured [6]. Personal, informal, intuitive, collective practices become central in this reflection, and the aim of the teacher is to create situations in which pupils can experiment various ways of retrieving and using information in order to build knowledge. The mediation process is human (intersubjective), spatial (organization and signage of the spaces), and technical [7]. Even if the teacher librarian does not usually follow a precise curriculum, he plays an important role in information and media literacy .

In our exploratory research project, we observe a specific school situation: supervised personal projects in which groups of pupils make a small interdisciplinary research project on a chosen topic. 16 years old pupils in high schools and vocational high schools were observed during their working process. We have tried to characterize typical transliterate activities which are cognitively distributed and situated. Supervised personal projects mix at least two different school disciplines and involve the teacher librarian who is in charge of helping and accompanying pupils in the information research process. The project lasts 12 weeks, pupils work in small groups ( 3 to 4 pupils) or individually in the case of the vocational high school. Their final project is evaluated during an oral examination where they have to present their work and working process, and they are given a mark for their examination.

In the first part of this article, we present our scientific protocol, which is based on an "ecological" approach of capturing pupils" information retrieval practices, and teachers' training practices. We focus on environments and interactions. In the second part, we explain why the global effectiveness of knowledge construction in this process depends on the regime of commitment of the teacher-librarians. In a third part, we consider the impact of this commitment on transliteracy practices and skills for the pupils.

\section{Transliterate practices in a learning context: terms and issues}

Information literacy has been extensively examined and discussed in research projects and surveys. In a long term project, our team in France tries to take into consideration pupils in their global information related activities, inside and outside school, and to capture their working processes, uses, productions, representations, performances. In a first step, we have followed some pupils in a school situation. 


\subsection{An ecological and interactionist approach of information practices}

We have chosen to consider the fundamental role of the global environment to observe information seeking and the use of practices and tools. We consider that information seeking activity is materially and socially situated [8]. We take into account "the social thickness of the forthcoming activity" [9]. We have built a research protocol which combines several qualitative methods, to integrate the question of the context: distant observation, explanation individual and collective interview and group focus, analysis of the traces. We have especially paid attention to all the actions taking place during the working time: reading and writing, organizing and communicating information using digital and non digital tools and sources.

The explanatory interview's goal is to make pupils verbalize their actions and then take part in a process. It complements observation with interpretation. We do not ignore that describing and explaining an action, which does not necessarily means conceptualizing, is difficult. Elocutionary action within the totality of the working process allows the capture of the "logic of methods". The cognitive relationship between the subject, the action and the discourse is taken into consideration, designated as "speaking" by Vermersch [10]. Our research protocol relies on a comprehensive recording of speaking on what is being realized as well as description of the situation. The data records (recordings, note books, usb keys, final project presentations) have been shared among researchers.

\subsection{Contexts and research protocol}

We worked in four different contexts in order to make comparisons: two different general high schools from two geographically and socially distant fields and two vocational high schools (only one has already been visited). In these schools, we have observed the pupils' research process with methods that can be defined as focused ethnography [11]. During short term and regular visits, we sat among groups of 3 to 4 pupils and made direct observation, recorded their exchanges with a digital voice recorder, took notes and memos with an observation grid and made unstructured interviews with the pupils. When we noticed some changes, important or intriguing elements in the state of action, we made the pupils explain the sense and interpretation of what they were doing: when a pupil left the group, when there was a change of activity, when a new negotiation among pupils started, when a teacher came, when they discussed their methods, practices, tools, etc. Pupils were very cooperative, soon forgot our long term presence and became used to seeing us settle our recorders and notes among them. We tried to be as discreet as possible so as not to interrupt their working process and their exchanges. 


\section{The role of the teacher librarian in the construction of an information culture}

\subsection{Personalization of an institutional arrangement}

The school situations that we have observed are institutional arrangements. They are designed to lead pupils to the building of competencies and knowledge. They are normative and give a specific role to the actors, which behavior is expected [12]. But each individual has his or her own understanding and a certain freedom of action inside the framework of the arrangement. We consider the situation as one driven toward information literacy and empowerment of the individuals on their information needs. We are also aware of the way some teacher librarians appropriated the situation to assert their position and to claim their specific responsibility on a corpus of knowledge, using a range of aims, methods and evaluating activities, and a didactic work on scientific notions in order to make them teachable to pupils.

Thus, supervised personal projects represent a challenge for the teacher librarians, among whom some have endorsed the global organization of the projects. Two different situations were observed. In the first one, the teacher librarians endorse the whole organization and management of the projects, coordinate all the teachers and classes. They are always present during the workshops, with the subject teachers. They demand precise working devices: a folder has to be handed in, describing the information research process on the topics. During the work on this file, pupils are trained to regularly use the library catalog and data bases, to evaluate information, write a bibliography, analyse fiability and reliability of a web site. They actively participate in the evaluation of the pupils' work and the final projets. In the second situation, facing the same academic situation, the role of the teacher librarian is quite different. The organization of the classes makes the management of all groups impossible. No specific training time or resource presentation is provided. The teachers do what they can in a situation they are not able to manage. They help pupils and teachers individually, provide documents and guidance, but do not have the capacity to impel a global, directive frame. Between these two opposite situation, the vocational high school offers a third model of a bicephalous management of the projects with the teacher librarian and the subject teacher. They are always present together and make a two-voices directive guidance of the pupils during their working process.

\subsection{Creation of didactic and pedagogic tools}

The will to progress on the building of an information culture relies on a set of didactic and pedagogic tools which are designed by the teacher librarians for the pupils. In the first situation, they are given a working agenda, meant to plan their work and regularly describe it in specific documents, and working files to record their bibliographic researches. Some teacher librarians have become cognitive mediators, According to one of them "reflection on the information searching process is 
important for us as teacher librarians". He relies on distributed cognition tools, such as the note book which is supposed to sustain reflexivity. He thinks that "it is important to think about what you are doing, how you do it, why you do it, not to rely on chance. Note book is a thought and research process structuring tool". Exploring the pupils' notebooks, one can understand their ability to mobilize resources, tools and appropriate situations, to progress and overcome obstacles. In the second situation, teacher librarians do not have the control on the project management, and have hard time trying to propose didactic situations. Their main way of dealing with the project is to train and help pupils individually. In the third situation, the teacher librarian has built his own evaluation criteria based on the research and use of information in the project.

Finally, in all the situations, the fundamental role of the teacher librarian as a trainer is a guarantee of the individual's autonomy, consciousness of the working and cognitive design. To reach this goal, they manage training moments dedicated to information for the pupils.

\section{The impact of the teacher librarian's commitment on pupils' transliterate practices}

\subsection{Awareness of the « art of practice"}

During our research, we were able to evaluate the pupils' capability to organize their information environment, to coordinate the work among the members of the groups. There is a direct correlation between these capabilities and the success of the projects.

Elise and Leonie, for instance, study sects and have clearly organized the work distribution. While Léonie searches for information on history and definition of the sects, Elise works on the social relation side of the project: she gets appointments with people fighting against sects who she would like to interview, organizes the communication device, uses her Gmail account to select the mails according to their themes and their interest. Flavien and Déborah work together but hardly talk to each other. They sometimes have a meeting to check the progress of the work and trust each other. They are quite organized and create working devices which allow them to coordinate their work according to what the teachers ask for. Clara, Alessandrine, Malou and Pauline also work silently. They worked on the plan at the beginning of the project and shared the parts of it among themselves, according to their tastes and capacities. One of them is in charge of interviewing a politician. She writes down her questions according to the aim of the research, and lets all the other girls read the questions and add new ideas. She finally makes a compilation and sorting of all the questions. She is also in charge of hand-writing the notebook. She asks the other what they have found and what they plan for the week.

Despite what is commonly said on youngster information practices, they own an elaborate "art of practice" [13] and a strong consciousness of their practice and the management of their personal information system. They tend to invent ways of doing things which are not orthodox according to what they are taught, but are nonetheless efficient and explicable using thoughtful devices. We use the word grammatization of 
information to characterize the process of creative learning, construction of knowledge and competencies on information which lead to information culture or transliteracy.

This grammatization appears when pupils are induced to think about their own practices and criticize them according to their social, academic and individual needs, constructing formal from informal knowledge on information, media and computers. It relies on two conditions: the existence of intuitive but nonetheless efficient information practices, commonly acquired in social situations, and the presence of a teacher librarian who induces awareness and control of the practices. When one of these conditions is lacking the process cannot be completed. It was the case in some situations that we observed : when pupils have no or poor social experience of using information and when the teacher librarian has few occasions to interact with pupils, a strong difference among pupils is observed, which creates inequality: in this case, transliteracy will mainly depend on social conditions and not on education. In the third case, while the pupils' social conditions are not favorable to transfers between personal and school information practices or between different media, the role of the teacher librarian is important to compensate the lack or poverty of informal knowledge.

\subsection{The individual information potential [14]}

Our research on transliteracy practices shows how necessary it is to have a multidimensional information education based on the convergence of literacies, in order for the individuals to research, use and communicate information in a critical and creative way. It is important to let the « arts of practice » emerge during teaching times, and to make bridges between different learnings and between the learnings and the practices to settle a creativity based teaching program. In our research, a teacher librarian noticed the complexity and quality of a work which used several media: music, video, singing, space shiftings, dialogs. His advice to the pupils was to rely on the diverse know-how and use of various software and social networks. The teacher librarian interference helps pupils to benefit from their personal information uses and ordinary practices and to control their way of doing and behaving for an efficient information and communication approach. The pupils have a very positive feedback of the experience which makes them aware of the efficiency of their own practices. They testify that they have learnt by doing: the meaning of an information source, organization of data bases, creative writing and thinking.

If we add the quality of the final projects, we notice the impact of a socially situated information-based teaching program, articulated to clearly identify and define notions. Pupils have understood the notions of source, publication, use of data bases and open archives. Without the barrier of technical obstacles and reproductive methodologies, pupils become conscious of their own behavior. These competencies are necessary to develop the information potential, the "ability to improve information competency in terms of breadth and depth" [15]. This competency is necessary for the building of an information culture and has to be included in a proactive definition of the learning process which is founded on the individual's capacity to socially adapt to information and digital environments. 


\section{Conclusions and Discussion}

The research protocol that was chosen has been able to enhance what Michel de Certeau has called individuals" "art of practice", meaning the capacity of tinkering with, and arranging adapted devices and situations, creating one's own information environment, or adopting what Jacques Perriault calls "logics of uses" [16]. It enhances the commitment of the teacher librarians into the pupils' information inquiry and knowledge construction process which has a strong effect on their autonomy in research, selection and use of information and media for their project. A real cognitive construction of knowledge on information, not only based on pragmatic skills and useful competencies, requires a positive pedagogic activity. When a precise local curriculum is applied, pupils tend be to much more creative and conscious of their own practices and competencies. When no arrangement exists, social and cultural inequalities tend to be prevalent, although social interactions among pupils have also some efficiency to share some competencies. The question is now to generalize the appliance of a curriculum on project based activities in order to construct a culture of information.

\section{References}

1. American Library Association: Presidential Committee on Information Literacy. Final Report, Chicago: http://www .ala.org/acrl/publications/whitepapers/presidential (1989)

2. Lehmans, A : Information literacy : un lien entre information, éducation et démocratie. Esquisse, 50-51, 25-40 (2007)

3. Thomas, S. and al : Transliteracy: Crossing divides. http://www.uic.edu/htbin/cgiwrap/bin/ojs/index.php/fm/article/view/2060/1908 (2007)

4. Liu, A.: Translitteracies: le big bang de la lecture en ligne, http://www.inasup.com/ressources/dossiers-de-laudiovisuel/les-e-dossiers-delaudiovisuel/translitteraties-le-big-bang-de-1 (2012)

5. Liquète, V. : Can one speak of an "information transliteracy"? International Conference "Media and Information Literacy (MIL) for Knowledge Societies", 24-28 June, Moscow, Russian Federation, http://www.unesco.org/new/fileadmin/MULTIMEDIA/HQ/CI/CI/pdf/In_Focus/Liquete_t ext.pdf (2012)

6. Cordier, A : Et si on enseignait l'incertitude pour construire une culture de l'information?. Communication at the Colloque international COSSI, Poitiers, 19-20 juin.

http://archivesic.ccsd.cnrs.fr/docs/00/80/30/91/PDF/CORDIER_Et_si_on_enseignait_1_in certitude.pdf (2012)

7. Liquète, V., Gardiès, C., Fabre, I. : Faut-il repenser la médiation documentaire ? In Caune J. (ed.), "La (les) médiation(s) en SIC", Les Enjeux de l'Information et de la Communication, http://w3.u-grenoble3.fr/les_enjeux/pageshtml/art2010-dossier.php (2010)

8. Suchman, L.: Human et machine reconfigurations: plans and situated actions, Cambridge, Cambridge University Press (2007) 
9. Jeanneret, Y., Souchier, E., Le Marec, J. : Lire, écrire, récrire : objets, signes et pratiques des médias informatisés, Paris, BPI (2003)

10. Vermersch, P.: L'entretien d'explicitation. $2^{\text {nd }}$ ed., Issy-les-Moulineaux, ESF (1996)

11. Knoblauch, H.: Focused Ethnography. Forum Qualitative Sozialforschung, Forum: Qualitative Social Research,6(3), Art. 44, http://nbn-resolving.de/urn:nbn:de:0114fqs0503440 (2005)

12. Peeters, H., Charlier, P.: Contributions à une théorie du dispositif. Hermès, 25, 15-22 (1999)

13. Certeau, M. (de) : L'invention du quotidien. 1 : Arts de faire. $2^{\text {nd }}$ ed., Paris, Gallimard (2004)

14. Yoon, C.G.: A structural model of end-user computing competency and user performance», Knowledge-Based Systems, 21, (2008)

15. Chui Y. Y.: Design of a Measurement System of End-User Information Competency with a Case Study, Advances in Measurement Systems, Milind Kr S. (Ed.), InTech, Available from: http://www.intechopen.com/books/advances-in-measurement-systems/design-ofameasurement-system-of-end-user-information-competency-with-a-case-study (2010)

16. Perriault, J.: La logique de l'usage. Essai sur les machines à communiquer, Paris, L'Harmattan (2008) 